\title{
Exact Optimum Design of Segmented Thermoelectric Generators
}

\author{
M. Zare, ${ }^{1}$ H. Ramin, ${ }^{2}$ S. Naemi, ${ }^{1}$ and R. Hosseini ${ }^{1}$ \\ ${ }^{1}$ Mechanical Engineering Department, Amirkabir University of Technology, 424 Hafez Avenue, P.O. Box 15875-4413, Tehran, Iran \\ ${ }^{2}$ Center of Excellence in Design and Optimization of Energy Systems, School of Mechanical Engineering, \\ College of Engineering, University of Tehran, Tehran, Iran
}

Correspondence should be addressed to H. Ramin; hadi.ramin@ut.ac.ir

Received 11 December 2015; Revised 10 March 2016; Accepted 20 March 2016

Academic Editor: Pouria Ahmadi

Copyright (C) 2016 M. Zare et al. This is an open access article distributed under the Creative Commons Attribution License, which permits unrestricted use, distribution, and reproduction in any medium, provided the original work is properly cited.

A considerable difference between experimental and theoretical results has been observed in the studies of segmented thermoelectric generators (STEGs). Because of simplicity, the approximate methods are widely used for design and optimization of the STEGs. This study is focused on employment of exact method for design and optimization of STEGs and comparison of exact and approximate results. Thus, using new highly efficient thermoelectric materials, four STEGs are proposed to operate in the temperature range of 300 to 1300 kelvins. The proposed STEGs are optimally designed to achieve maximum efficiency. Design and performance characteristics of the optimized generators including maximum conversion efficiency and length of elements are calculated through both exact and approximate methods. The comparison indicates that the approximate method can cause a difference up to $20 \%$ in calculation of some design characteristics despite its appropriate results in efficiency calculation. The results also show that the maximum theoretical efficiency of $23.08 \%$ is achievable using the new proposed STEGs. Compatibility factor of the selected materials for the proposed STEGs is also calculated using both exact and approximate methods. The comparison indicates a negligible difference in calculation of compatibility factor, despite the considerable difference in calculation of reduced efficiency (temperature independence efficiency).

\section{Introduction}

Nowadays, the use of thermoelectric cooler and generator has become increasingly developed. The thermoelectric applications include electronic cooling, portable refrigerator, air conditioning, high-precision temperature measurement, and space applications. The thermoelectric method has outstanding features compared to the other energy conversion methods such as exclusion of moving parts, high reliability, and long life span [1]. In addition, there are several studies on the combined use of the thermoelectric technology with other energy conversion methods (e.g., steam and gas turbine) as an efficient way of harnessing waste heat in power plant and other industries [2]. However, the need for high temperature heat source and low efficiency is a remarkable challenge in the thermoelectric technology. Today, the first challenge has been overcome thanks to the abundant waste heat sources, high temperature exhausted gas of diesel engine [3], and so forth. However, so many studies have been done to increase the efficiency of thermoelectric applications and a lot is still needed. The effort to enhance thermoelectric efficiency can be classified into three categories: invention and development of highly efficient materials, segmentation, and cascading. The first two of them are discussed in the current study.

Invention and Development of Highly Efficient Materials. Thermoelectric efficiency not only depends on temperature, but also depends on physical properties of the material such as electrical and thermal conductivity and Seebeck coefficient. The effect of such properties on efficiency can be analysed using figure of merit (FOM or $Z$ ) or dimensionless figure of merit $(Z T)$. The higher the FOM, the higher the conversion efficiency. In this category, the attempts are inclined to enhance the performance of thermoelectric applications by modification of physical properties which results in the increase of FOM, that is, increase in Peltier coefficient, electrical conductivity, and thermal resistivity. Many studies have focused on this category. In particular, in recent years, with the advent of nanotechnology, many researchers have made attempts to develop thermoelectric materials with 


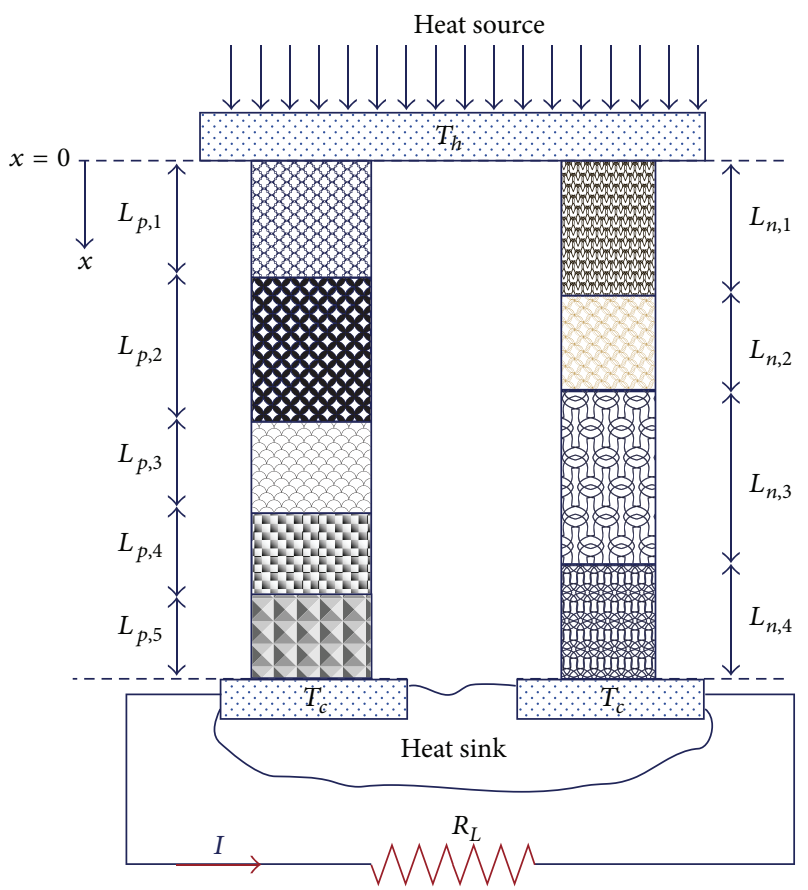

(a)

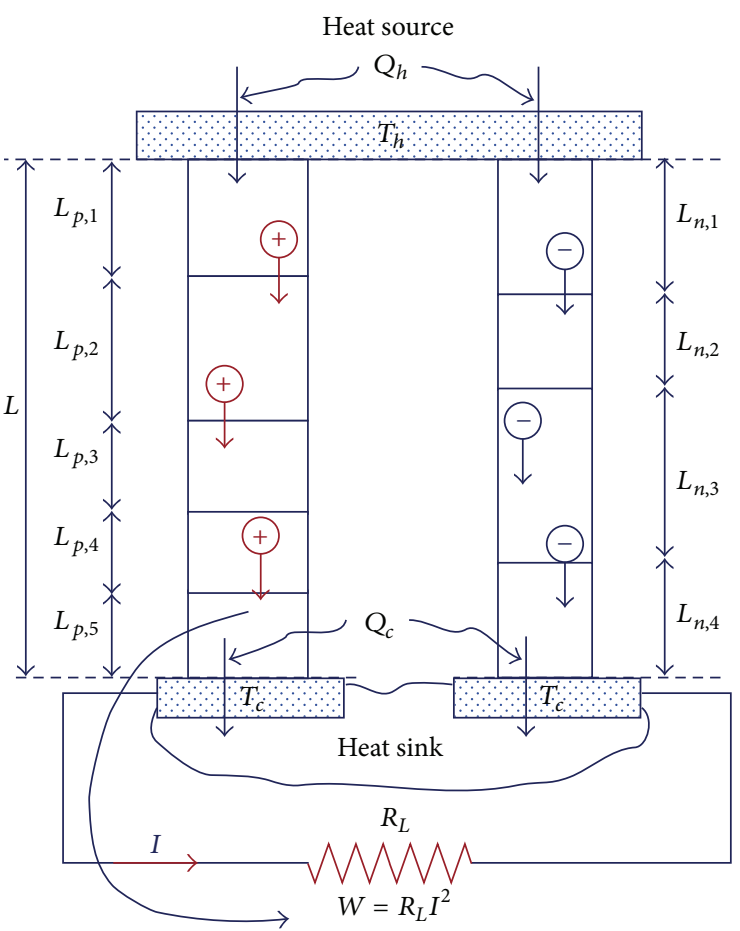

(b)

FIGURE 1: Schematic of a segmented thermoelectric generator.

higher FOM [4-7]. The remarkable achievements of Boston and MIT researchers can be mentioned $[8,9]$.

Segmentation. Considering the temperature dependence of FOM, so far, no material has been found with a satisfactory FOM within a sufficiently large temperature range (e.g., 300 to $1300 \mathrm{~K}$ ). Different materials have a satisfactory FOM only within a limited temperature range. Hence, the segmented thermoelectric devices have emerged (see Figure 1(a) which shows a segmented thermoelectric generator). In the segmented thermoelectric device, each material is supposed to be used in its own specific temperature range, in which it has a reasonable FOM. Numerous researches have been done in this category. Chen et al. [8] proposed a STEG for operation between 300 and $900 \mathrm{~K}$ and achieved theoretical efficiency of $15 \%$. Kang et al. [10] presented a $p$-type thermoelectric leg and claimed that $17 \%$ efficiency can be achieved experimentally. Snyder and Caillat [11] presented a STEG, considering compatibility factor. With the assumption of negligible contact resistance and adiabatic outside surface area, they achieved $18.1 \%$ efficiency theoretically in temperature range of 25 and $1000^{\circ} \mathrm{C}$.

Efficiency calculation is one of the most important parts of thermoelectric generators research, as it is important in other energy conversion methods. Due to importance of efficiency, several researches have been conducted on the methods of efficiency calculation of thermoelectric generators. Sherman et al. [12] presented a comprehensive method for calculation of performance of thermoelectric devices. With the advent of segmented thermoelectric systems, Swanson et al. [13] offered an approximate method for calculation of performance and design of segmented thermoelectric systems. Moore [14] calculated the performance characteristics of a feasible STEG using the exact and Swanson et al.s methods and compared the results. Moore did not design or optimize a STEG; he only focused on performance calculation of a predesigned generator. El-Genk and Saber [15] improved Swanson et al.s method. Their model uses volume average to calculate thermoelectric properties rather than temperature average of Swanson et al.s method. Until now, due to the widespread application of STEGs, the researchers work on a new methodology for calculation of the efficiency of the STEGs $[16,17]$.

Considering FOM as the only factor in design of STEGs can adversely affect the thermoelectric efficiency. Therefore, another parameter (called compatibility factor) must be considered in design of STEGs. The compatibility factor also shows whether segmentation or cascading should be used in different conditions [18].

One of the most important steps in exergy analysis of energy systems is identification of waste heat sources in order to minimize exergy destruction. The thermoelectric technology is a promising way to harness the waste heat. Thus, the thermoelectric generators and specially STEGs are of importance in exergy optimization. A considerable difference between experimental and theoretical results (approximate methods) has been observed in the studies of STEGs [15]. Although a major portion of the differences can result from contact resistance and experimental uncertainty, it seems necessary to confirm the validity of theoretical results. Up to now, all of the thermoelectric researchers use the approximate methods for design and optimization of the STEGs, because 


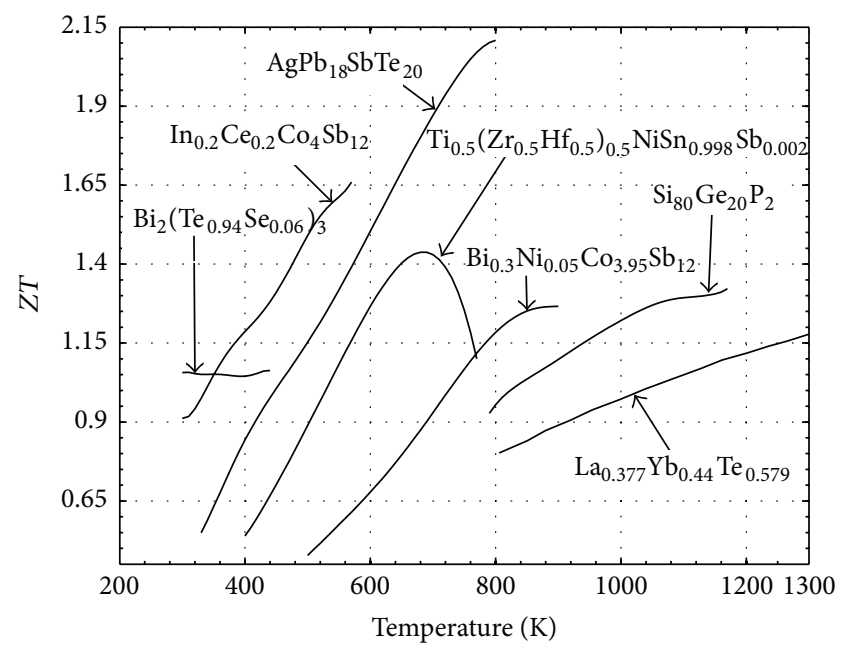

(a)

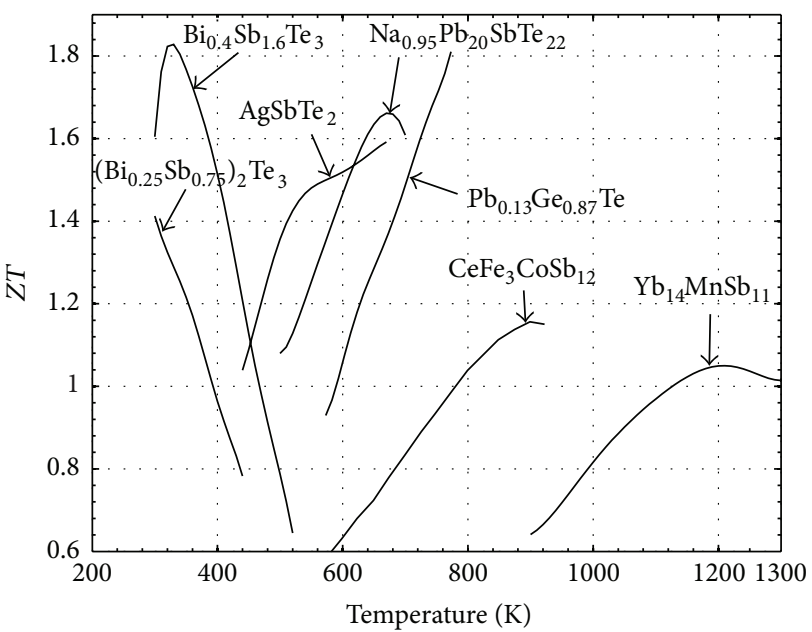

(b)

FIgURE 2: Temperature dependence of dimensionless figure of merit for (a) $n$-type and (b) $p$-type materials.

of their simplicity. But this may be a cause of the difference between experimental and theoretical results. There was lack of using exact method for optimization of STEGs in the literature; therefore, application of exact method can bridge the gap between theoretical and experimental results [15-17]. Considering this fact, the main objectives of this study can be categorized as follows:

(i) In order to design and optimize STEGs, at the first step, the chemically and physically modified thermoelectric materials are reviewed. Thus, the materials which have high efficiency in a temperature range are selected. Then, four STEGs are proposed for optimization process.

(ii) As the main objective of this study, the proposed STEGs are optimized using the exact method rather than the common simple approximate methods. Then, the design and performance characteristics of the STEGs are calculated through exact method.

(iii) Finally, the design and performance characteristics of the proposed STEGs are also calculated through common approximate methods. Then, the results of exact and approximate methods are compared.

\section{Selection of Materials}

In this paper, a major study has been done on the latest known thermoelectric materials, the best of which have been applied for the design of a thermoelectric generator. Due to the temperature dependence of FOM, the materials with a satisfactory FOM in a specific temperature range have been selected. Figures 2(a) and 2(b) show the variation of FOM with temperature for $n$-type and $p$-type legs, respectively. Two arrangements have been optimized for each type of leg. Next, by considering different combinations, four STEGs have been proposed and analysed. The materials used in the mentioned arrangements, as well as temperature ranges for each arrangement, are presented in Table 1.

\section{Optimization and Performance Calculations}

3.1. Exact Method. Performance calculation methods of single-segmented generator were introduced by Sherman et al. [12]. Efficiency of a thermoelectric generator is defined by the following relation:

$$
\eta=\frac{W}{Q_{h}}
$$

where $W$ and $Q_{h}$ are output power and input heat, respectively (see Figure 1(b)). Assuming ideal condition,

$$
W=R_{L} I^{2}=Q_{h}-Q_{c}
$$

where $R_{L}, I$, and $Q_{c}$ are load resistance, electrical current, and output heat, respectively. Using relations (1) and (2) for given $Q_{h}$ and $Q_{c}$, it is possible to calculate efficiency. $Q_{c}$ and $Q_{h}$ are determined by energy balance in cold and hot junctions as follows [12]:

$$
\begin{aligned}
Q_{c} & =\pi_{c} I+A_{p} k_{p}\left(T_{c}\right) \frac{d T_{p}}{d x}(L)+A_{n} k_{n}\left(T_{c}\right) \frac{d T_{n}}{d x}(L), \\
Q_{h} & =\pi_{h} I+A_{p} k_{p}\left(T_{h}\right) \frac{d T_{p}}{d x}(0)+A_{n} k_{n}\left(T_{h}\right) \frac{d T_{n}}{d x}(0),
\end{aligned}
$$

where $A, k$, and $\pi$ are cross section area, thermal conductivity, and Peltier coefficient, respectively. The subscripts $c, h, p$, and $n$ refer to cold junction, hot junction, $p$-type leg, and $n$-type leg, respectively. Equation (3) denotes that it is necessary to determine temperature gradient as well as the electrical current passing through the legs to calculate $Q_{c}$ and $Q_{h}$. Therefore, it is essential to determine the temperature 
TABLE 1: The materials of the proposed arrangements and their operation temperature range.

\begin{tabular}{|c|c|c|c|}
\hline $\begin{array}{l}p 1 \\
\text { (temperature range) }\end{array}$ & $\begin{array}{c}p^{2} \\
\text { (temperature range) }\end{array}$ & $\begin{array}{c}n 1 \\
\text { (temperature range) }\end{array}$ & $\begin{array}{c}n 2 \\
\text { (temperature range) }\end{array}$ \\
\hline $\begin{array}{l}\left(\mathrm{Bi}_{0.25} \mathrm{Sb}_{0.75}\right)_{2} \mathrm{Te}_{3}[19] \\
(300-440)\end{array}$ & $\begin{array}{c}\mathrm{Bi}_{0.4} \mathrm{Sb}_{1.6} \mathrm{Te}_{3}[20] \\
(300-520)\end{array}$ & $\begin{array}{c}\mathrm{Bi}_{2}\left(\mathrm{Te}_{0.94} \mathrm{Se}_{0.06}\right)_{3}[21] \\
(300-440)\end{array}$ & $\begin{array}{c}\mathrm{In}_{0.2} \mathrm{Ce}_{0.2} \mathrm{Co}_{4} \mathrm{Sb}_{12}[22] \\
(300-570)\end{array}$ \\
\hline $\begin{array}{l}\mathrm{AgSbTe}_{2}[23] \\
(440-670)\end{array}$ & $\begin{array}{c}\mathrm{Na}_{0.95} \mathrm{~Pb}_{20} \mathrm{SbTe}_{22}[24] \\
(520-700)\end{array}$ & $\begin{array}{c}\mathrm{AgPb}_{18} \mathrm{SbTe}_{20}[25] \\
(440-800)\end{array}$ & $\begin{array}{c}\mathrm{AgPb}_{18} \mathrm{SbTe}_{20}[25] \\
(570-800)\end{array}$ \\
\hline $\begin{array}{l}\mathrm{Pb}_{0.13} \mathrm{Ge}_{0.87} \mathrm{Te}[26] \\
(670-770)\end{array}$ & $\begin{array}{c}\mathrm{Pb}_{0.13} \mathrm{Ge}_{0.87} \mathrm{Te}[26] \\
(700-770)\end{array}$ & $\begin{array}{l}\mathrm{Si}_{80} \mathrm{Ge}_{20} \mathrm{P}_{2}[27] \\
\quad(800-1200)\end{array}$ & $\begin{array}{c}\mathrm{Si}_{80} \mathrm{Ge}_{20} \mathrm{P}_{2}[27] \\
(800-1200)\end{array}$ \\
\hline $\begin{array}{l}\mathrm{CeFe}_{3} \mathrm{CoSb}_{12}[28] \\
(770-920)\end{array}$ & $\begin{array}{c}\mathrm{CeFe}_{3} \mathrm{CoSb}_{12}[28] \\
(770-920)\end{array}$ & $\begin{array}{c}\mathrm{La}_{0.377} \mathrm{Yb}_{0.44} \mathrm{Te}_{0.579}[29] \\
(1200-1300)\end{array}$ & $\begin{array}{c}\mathrm{La}_{0.377} \mathrm{Yb}_{0.44} \mathrm{Te}_{0.57}[29] \\
\quad(1200-1300)\end{array}$ \\
\hline $\begin{array}{l}\mathrm{Yb}_{14} \mathrm{MnSb}_{11}[30] \\
(920-1300)\end{array}$ & $\begin{array}{l}\mathrm{Yb}_{14} \mathrm{MnSb}_{11}[30] \\
(920-1300)\end{array}$ & - & - \\
\hline
\end{tabular}

distribution in legs. The temperature distribution of a singlesegmented leg is calculated through the following equation [31]:

$$
\begin{array}{r}
\frac{d}{d x}\left[k(T) T^{\prime}(x)\right]-\gamma(T) J T^{\prime}(x)+\rho(T) J^{2}=0, \\
\gamma(T)=T \frac{d \alpha}{d T}, J=\frac{I}{A} .
\end{array}
$$

In the above equation, $T^{\prime}$ is derivative of temperature with respect to $x . \gamma$ and $J$ are Thomson coefficient and current density, respectively. It is evident that solving such equation requires knowing exactly how the thermoelectric properties change with temperature. Equation (4) is solved for each leg using the following change of variable:

$$
\begin{aligned}
& y(T)=-\frac{k(T)}{J d x / d T} \\
& \text { or } u=-\frac{J}{k(T) d T / d x} .
\end{aligned}
$$

Hence, (4) can be written as the following:

$$
\begin{aligned}
\frac{d y}{d T} & =-\gamma(T)-\frac{\rho(T) K(T)}{y(T)} \\
\text { or } \frac{d u}{d T} & =(\gamma(T)+\rho(T) K(T) y(T)) u^{2},
\end{aligned}
$$

where $u$ represents relative current density. In exact method, the above equation can be solved using the variable substitution of (5) and considering an initial condition for $u(T)$ or $y(T)$. The solution results include determination of electrical current and temperature distribution, two mentioned necessary factors for calculation of $Q_{c}$ and $Q_{h}$. Consequently, the efficiency is determined. Next, the efficiency can be maximized by repeating the process with different initial conditions.

In this study, specific modifications must be applied to this process due to the fact that more than one material is used in each leg and the Peltier heat is also presented in each interface. To solve the problem, (4) is solved separately for each segment, and the following continuity conditions are applied at the interfaces for $n$-type and $p$-type legs, respectively [14]:

$$
\begin{aligned}
& k_{j} A_{j} T_{j}^{\prime}=k_{j+1} A_{j+1} T_{j+1}^{\prime}+T I\left(\alpha_{j+1}-\alpha_{j}\right), \\
& k_{j} A_{j} T_{j}^{\prime}=k_{j+1} A_{j+1} T_{j+1}^{\prime}-T I\left(\alpha_{j+1}-\alpha_{j}\right) .
\end{aligned}
$$

Electrical and thermal conductivity and Seebeck coefficient of the materials have been obtained from references given in Table 1 . Then, (4) has been solved numerically using $\Delta T=1$ and assuming initial condition for $u\left(T_{h}\right)$ or $y\left(T_{h}\right)$.

Integrating of (4) gives (8) which is used for calculation of current density:

$$
\int_{T_{c}}^{T_{h}} k(T) u(T) d T=-J L .
$$

The length of each segment is calculated using (8) and conservation of electrical current.

It is common that the cross section area of $p$-leg is assumed to be constant and the cross section of $n$-leg is optimized. Hence, $A_{n \text {,opt }}$ is obtained using current density, conservation of electrical current, and the assumption of $A_{p}=100 \mathrm{~mm}^{2}$. Consequently, the cross section area ratio is calculated.

The internal resistance $\left(R_{\text {int }}\right)$ is calculated using material properties and relation $R=\rho L / A$. Finally, $R_{L \text {,opt }}$ and the resistance ratio are calculated through (2).

3.2. Swanson et al.'s Method. In approximate methods such as Swanson et al.'s method, approximate equations are used, rather than (4), to determine the efficiency. In fact, Swanson et al's method includes calculation of performance characteristics on the basis of temperature average properties. In this method, an approximate relation for efficiency is derived in terms of temperature average properties. The next step is optimization of all characteristics including the ratios of cross section area and resistance to maximize the efficiency $\left(A_{n} / A_{p}, R_{L} / R_{\text {int }}\right)$. The electrical current and temperature distribution required in exact method are the current and element lengths in Swanson et al's method. The calculation of the mentioned parameters through Swanson et al's method is based on solution of energy-balance equation on the interfaces [13], which is different from solution of overall energy-balance equation (4) in exact method. 


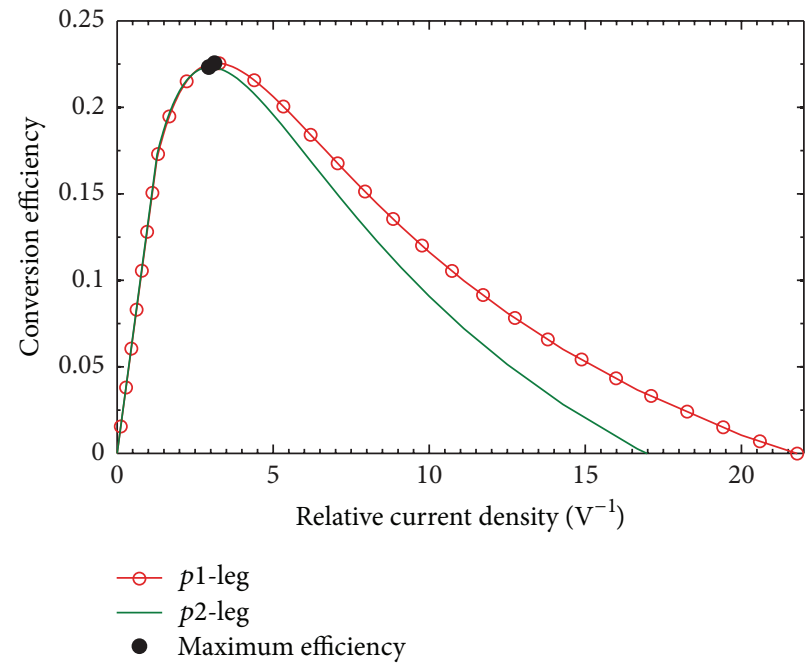

(a)

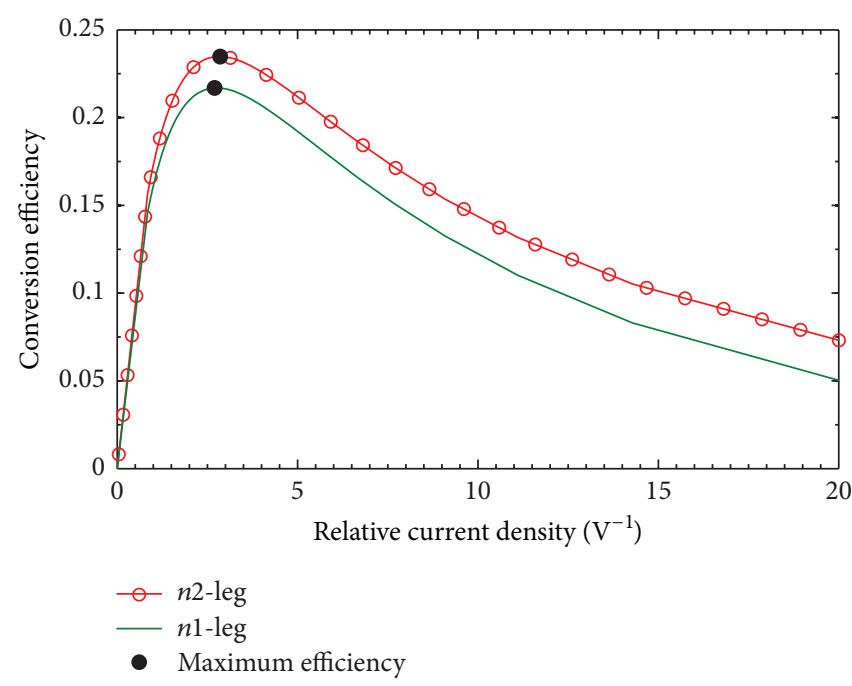

(b)

FiguRE 3: Variation of conversion efficiency versus $u\left(T_{h}\right)$ (relative current density at $T_{h}$ ) for (a) p1-leg and $p 2$-leg and (b) $n 1$-leg and $n 2$-leg.

3.3. Compatibility Factor (Exact and Approximate Methods). Compatibility factor is an important parameter which must be considered in addition to FOM in the design of STEGs [18]. Compatibility factor indicates whether the use of two materials in an arrangement has a positive or negative effect on reduced efficiency. The compatibility factor is the relative current density in which reduced efficiency of a material or arrangement is maximized. Reduced efficiency is an intrinsic characteristic of a material which eliminates the effect of temperature range from the total efficiency. It is defined in the following form:

$$
\begin{aligned}
& \eta_{r}=\frac{\eta}{\eta_{c}} \\
& \eta_{c}=\frac{\Delta T}{T_{h}},
\end{aligned}
$$

where $\eta$ and $\eta_{c}$ are the absolute and Carnot efficiency, respectively. In order to add a new material to an original material or arrangement, it is necessary to calculate the compatibility factor of the two elements. If the compatibility factor of the new material differs by a factor of two or less, reduced efficiency of the resulting arrangement increases, which means the two elements are compatible [32]. Otherwise, it is said that they are incompatible and segmentation leads to a decrease in reduced efficiency. Compatibility factor of each element is the relative current density of the element at its maximum reduced efficiency. In order to calculate compatibility factor, (4) is solved for each material by supposing a boundary condition for $y$, and the reduced efficiency is obtained. Next, by changing the boundary condition of $y$, reduced efficiency is maximized. The compatibility factor is the relative current density corresponding to the maximized reduced efficiency. Owing to the fact that compatibility factor is temperature dependent, it is calculated at a specific temperature. Also, the compatibility factor should not change considerably with temperature; such materials are called self-compatible. In approximate method, the calculation of compatibility factor is the same as exact method but the reduced efficiency is calculated through the following relation [18]:

$$
\begin{aligned}
& \eta_{r}=\frac{u(\rho k / \alpha)(1-u(\rho k / \alpha))}{u(\rho k / \alpha)+1 / Z T}, \\
& Z=\frac{\alpha^{2}}{\rho k} .
\end{aligned}
$$

At a specific temperature, the curve of reduced efficiency versus current density is plotted using (10), and then the compatibility factor is obtained.

In this study, the proposed STEGs have been optimally designed to achieve maximum efficiency using both exact and approximate methods (exact and Swanson et al.s methods). The design and performance characteristics of the optimized STEGs have been calculated using both methods and results have been compared. Compatibility factors of the proposed arrangements have also been calculated through both exact and approximate methods and results have been compared.

\section{Results and Discussion}

4.1. Analysis of the Proposed Generators. In this paper, two arrangements have been suggested for each $n$-type and $p$ type leg using the best available thermoelectric materials. Then, with the combination of them, four STEGs have been proposed. Table 1 shows the arrangements of legs as well as their temperature range. The proposed STEGs have been optimized in order to achieve maximum efficiency. Design and performance characteristics of the optimized STEGs including length of elements, electrical current, cross section ratio, and resistance ratio have been calculated using exact method. The overall length of each leg and the cross section of $p$-type legs are assumed to be $10 \mathrm{~mm}$ and $100 \mathrm{~mm}^{2}$, respectively.

Figures 3(a) and 3(b) indicate the efficiency of p-type and $n$-type legs versus relative current density, respectively, 
TABLE 2: Design and performance characteristics of $p 1-n 1$ and $p 1-n 2$ generators at maximum efficiency, calculated through both exact and Swanson et al.s [13] methods. The differences between Swanson et al.s and exact results are shown in parenthesis. $A_{p}$ and $L$ are assumed as constant inputs of the optimization process.

\begin{tabular}{|c|c|c|c|c|}
\hline Parameters & $\begin{array}{l}\text { Swanson method } \\
(p 1-n 1)\end{array}$ & $\begin{array}{l}\text { Exact method } \\
\quad(p 1-n 1)\end{array}$ & $\begin{array}{l}\text { Swanson method } \\
\qquad(p 1-n 2)\end{array}$ & $\begin{array}{l}\text { Exact method } \\
\quad(p 1-n 2)\end{array}$ \\
\hline$L$ (mm) (input) & 10 & 10 & 10 & 10 \\
\hline$A_{p}\left(\mathrm{~mm}^{2}\right)$ (input) & 100 & 100 & 100 & 100 \\
\hline Calculated $Q_{\text {in }}(W)$ & $37.61(4.1)$ & 39.24 & $38.15(1.2)$ & 38.63 \\
\hline Calculated $Q_{\text {rej }}(W)$ & $31.48(2.9)$ & 30.58 & $31.13(4.8)$ & 29.71 \\
\hline Calculated $P_{e}(\mathrm{~W})$ & $8.57(1.03)$ & 8.65 & $9.12(2.3)$ & 8.92 \\
\hline Residual power $\left(Q_{\text {in }}-Q_{\text {rej }}-P_{e}\right)(\mathrm{W})$ & -2.43 & - & -2.10 & - \\
\hline Calculated peak efficiency, $\eta(\%)$ & $22.77(3.2)$ & 22.06 & $23.91(3.6)$ & 23.00 \\
\hline$A_{n, \mathrm{opt}}\left(\mathrm{mm}^{2}\right)$ & $83.49(7.7)$ & 77.51 & $92.81(14.5)$ & 81.08 \\
\hline$L_{p, 1}, L_{p, 2}, L_{p, 3}, L_{p, 4}, L_{p, 5}(\mathrm{~mm})$ & $\begin{array}{c}2.656,3.263,1.529 \\
0.808,1.7350(5.05)\end{array}$ & $\begin{array}{c}2.636,3.199,1.514 \\
0.823,1.827\end{array}$ & $\begin{array}{c}2.661,3.262,1.532 \\
0.807,1.728(5.4)\end{array}$ & $\begin{array}{c}2.636,3.199,1.514 \\
0.823,1.827\end{array}$ \\
\hline$L_{n, 1}, L_{n, 2}, L_{n, 3}, L_{n, 4}(\mathrm{~mm})$ & $\begin{array}{c}0.488,5.716,2.504 \\
1.283(9.12)\end{array}$ & $\begin{array}{c}0.447,5.734,2.543, \\
1.275\end{array}$ & $\begin{array}{c}0.533,6.231,1.667 \\
1.559(8.09)\end{array}$ & $\begin{array}{c}0.493,6.240,1.711, \\
1.556\end{array}$ \\
\hline$I(\mathrm{~A})$ & $28.11(7.1)$ & 30.27 & $28.75(5.01)$ & 30.27 \\
\hline$R_{L, \text { opt }}(\mathrm{m} \Omega)$ & $10.8(14.9)$ & 9.4 & $11.0(13.4)$ & 9.7 \\
\hline
\end{tabular}

which are calculated using exact method. In this study, absolute values of $u$ and $y$ have been used. Sherman et al. [12] mentioned that if the efficiency changes in the range of $0.3-0.03$, the value of $u$ will change in the range of $0.9-$ 3.57 ( $y: 0.28-1.12$ ). As can be inferred from the figures, the optimum value of $u$ is 2.7 and 2.85 for $n$-type and 3.125 and 2.95 for $p$-type, respectively, which shows great agreement with Sherman et al's data. The maximum efficiency for the p1-leg and p2-leg equals $22.56 \%$ and $22.32 \%$, respectively, while it equals $21.69 \%$ and $23.48 \%$ for the $n 1-\operatorname{leg}$ and $n 2-l e g$, respectively.

Four generators resulting from combination of the legs have been presented in Tables 2 and 3. The computed design characteristics of the generators at maximum efficiency using the exact method are shown in these tables as well. The highest efficiency is $23.08 \%$, which belongs to the generator resulting from the combination of $p 1$ and $n 2$, which shows $4.98 \%$ increase in comparison with Snyder arrangement which is $18.1 \%$ [11]. The $p 1-n 2$ generator has also been designed for operating between 300 and $973 \mathrm{~K}$ in order for making comparison with Fleurial and Caillat's arrangement $[15,33]$. The output power, inlet heat, and outlet heat of the mentioned generator are equal to $6.67 \mathrm{~W}, 31.52 \mathrm{~W}$, and $24.851 \mathrm{~W}$, respectively, in the same temperature range. These values are by far less than those of Fleurial and Caillat's generator at the same temperature range. However, the efficiency of the current generator is by far higher than that of Fleurial and Caillat (i.e., $21.28 \%$ compared with $13.29 \%$ ). The mentioned results are mainly caused by a decrease in thermal conductivity which has been a basis for most of the recent works in the field of new thermoelectric materials especially where nanotechnology is used.

Since the amount of output power is of great importance in most applications, the $p 1-n 2$ generator has also been designed at maximum power (instead of at maximum efficiency). The results are shown in Table 4.
Nevertheless, it is explained in the following section that such design cannot be an ideal design because the system is not so-called load-following [15]. According to Table 2, the power generated by such generator is $8.92 \mathrm{~W}$ at maximum efficiency and $9.33 \mathrm{~W}$ at maximum power design. Also, the efficiency reduces from $23.08 \%$ to $22.72 \%$, revealing an increase of $4.62 \%$ in power in exchange for $1.58 \%$ decrease in efficiency. It is remarkable that electrical current has undergone $17.33 \%$ increase and the optimum external resistance decreases by $23.71 \%$. Figures $4(a)$ and 4(b) show the variation of generated power per unit cross section area and the inlet heat flux versus relative current density for $p$-type and $n$-type legs, respectively. The solid circles and open triangles show maximum efficiency and maximum power, respectively. Generator's function in load-following and non-load-following mode has been indicated by full lines and dotted lines, respectively. Therefore, the operation point of generator should be selected in fully lined portion of the curve. According to the figures, the design of generator at maximum power results in loss of load-following, while design at maximum efficiency keeps the generator in a range with load-following [15].

4.2. Evaluation of Generators Using Compatibility Factor. Variations of reduced efficiency with respect to relative current density for $n$-type and $p$-type legs at $T_{\mathrm{av}}$ have been calculated by exact method and are presented with solid lines in Figures 5 and 6, respectively. The solid circles show the maximum of reduced efficiency. The values of relative current density corresponding to these maximum points represent the compatibility factor of each segment. The curves of $p$-type and $n$-type legs reveal that, in general, the compatibility factors of materials are better for $p$-type than for $n$-type. However, the curves cannot be used to investigate the whole leg compatibility. This is due to the fact that when a new material is added to an original arrangement, 
TABLE 3: Design and performance characteristics of $p 2-n 1$ and $p 2-n 2$ generators at maximum efficiency, calculated through both exact and Swanson et al.s [13] methods. The differences of Swanson et al.'s results compared to the exact ones are shown in parenthesis. $A_{p}$ and $L$ are assumed as constant inputs of the optimization process.

\begin{tabular}{|c|c|c|c|c|}
\hline Parameters & $\begin{array}{l}\text { Swanson method } \\
\qquad(p 2-n 1)\end{array}$ & $\begin{array}{l}\text { Exact method } \\
\quad(p 2-n 1)\end{array}$ & $\begin{array}{l}\text { Swanson method } \\
(p 2-n 2)\end{array}$ & $\begin{array}{l}\text { Exact method } \\
\quad(p 2-n 2)\end{array}$ \\
\hline$L$ (mm) (input) & 10 & 10 & 10 & 10 \\
\hline$A_{p}\left(\mathrm{~mm}^{2}\right)$ (input) & 100 & 100 & 100 & 100 \\
\hline Calculated $Q_{\text {in }}(W)$ & $37.91(0.62)$ & 38.15 & $38.46(2.4)$ & 37.57 \\
\hline Calculated $Q_{\text {rej }}(W)$ & $31.55(5.99)$ & 29.77 & $31.21(7.8)$ & 28.94 \\
\hline Calculated $P_{e}(\mathrm{~W})$ & $8.58(2.4)$ & 8.38 & $9.13(5.8)$ & 8.63 \\
\hline Residual power $\left(Q_{\text {in }}-Q_{\text {rej }}-P_{e}\right)(\mathrm{W})$ & -2.22 & - & -1.88 & - \\
\hline Calculated peak efficiency, $\eta(\%)$ & $22.63(3.0)$ & 21.97 & $23.74(3.3)$ & 22.97 \\
\hline$A_{n, \mathrm{opt}}\left(\mathrm{mm}^{2}\right)$ & $83.38(13.2)$ & 73.65 & $92.71(20.3)$ & 77.04 \\
\hline$L_{p, 1}, L_{p, 2}, L_{p, 3}, L_{p, 4}, L_{p, 5}(\mathrm{~mm})$ & $\begin{array}{c}2.570,3.167,1.050 \\
1.821,1.382(5.11)\end{array}$ & $\begin{array}{c}2.562,3.132,1.042 \\
1.808,1.456\end{array}$ & $\begin{array}{c}2.573,3.164,1.052 \\
1.825,1.376(5.5)\end{array}$ & $\begin{array}{c}2.562,3.132,1.042 \\
1.808,1.456\end{array}$ \\
\hline$L_{n, 1}, L_{n, 2}, L_{n, 3}, L_{n, 4}(\mathrm{~mm})$ & $\begin{array}{c}0.488,5.716,2.504 \\
1.283(9.03)\end{array}$ & $\begin{array}{c}0.447,5.734,2.543, \\
1.275\end{array}$ & $\begin{array}{c}0.532,6.232,1.668, \\
1.560(7.99)\end{array}$ & $\begin{array}{c}0.493,6.240,1.711 \\
1.556\end{array}$ \\
\hline$I(\mathrm{~A})$ & $28.01(2.63)$ & 28.76 & $28.65(0.4)$ & 28.76 \\
\hline$R_{L, \mathrm{opt}}(\mathrm{m} \Omega)$ & $10.9(7.9)$ & 10.1 & $11.1(6.7)$ & 10.4 \\
\hline
\end{tabular}

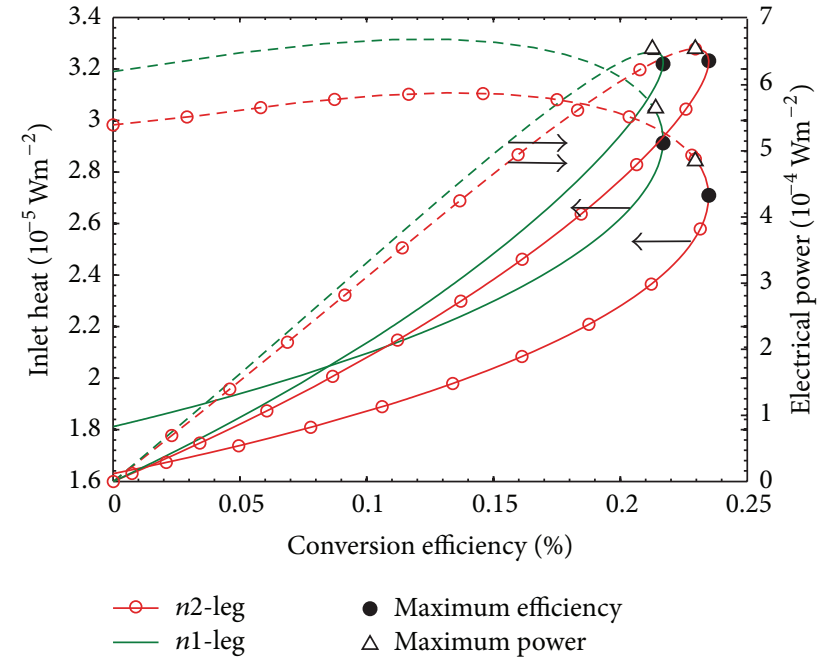

(a)

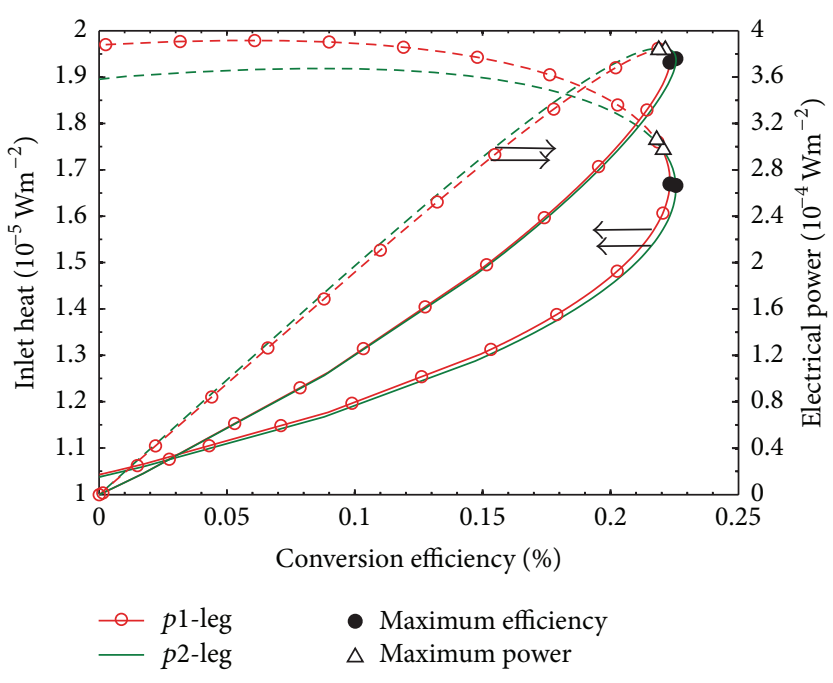

(b)

FIGURE 4: Electrical output power per cross section area and input heat flux versus conversion efficiency for (a) p1-leg and $p 2-1$ leg and (b) $n 1$-leg and $n 2$-leg which have been calculated through exact method.

the compatibility of the original arrangement as a whole and new material must be assessed, but the curves are plotted for each material separately. Therefore, they are only useful for a general assessment of materials' compatibility. In order to clarify the subject, the change of reduced efficiency of legs with increasing number of elements has been shown in Table 5. The table reveals that the materials used in the pl-leg are compatible; and adding material increases the reduced efficiency of the resulting assembly. Also, in p2leg, the materials are compatible but the first two materials are on the border of compatibility and incompatibility. For the arrangements $n 1$ and $n 2$, only the first three materials are compatible, and the fourth material is incompatible with them; therefore, adding it to the arrangement leads to a decrease in the reduced efficiency of the arrangement as a whole. The materials used would be compatible, if the $n$-legs were used in temperature range of 300 and $1200 \mathrm{~K}$. However, owing to the fact that $p$-legs have been used in range of 300 and $1300 \mathrm{~K}, n$-legs should be used in the same temperature range to preserve consistency. Our search for a material with a better compatibility factor did not lead to any satisfactory results in the mentioned temperature range. Therefore, these arrangements have been proposed.

4.3. Evaluation of Approximate Methods. The optimized generators have also been designed using Swanson et al's method at maximum efficiency. The calculated performance and design characteristics are shown in Tables 2 and 3 and 


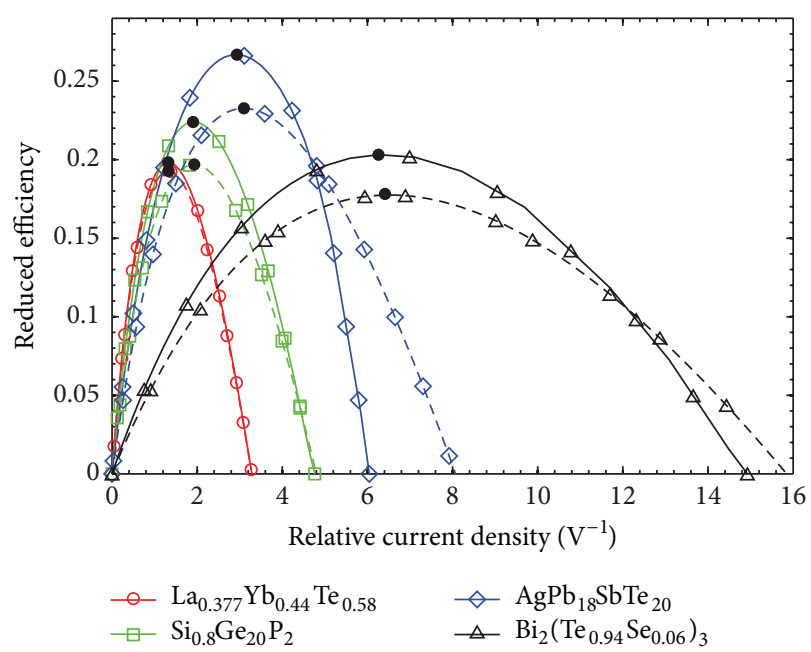

(a)

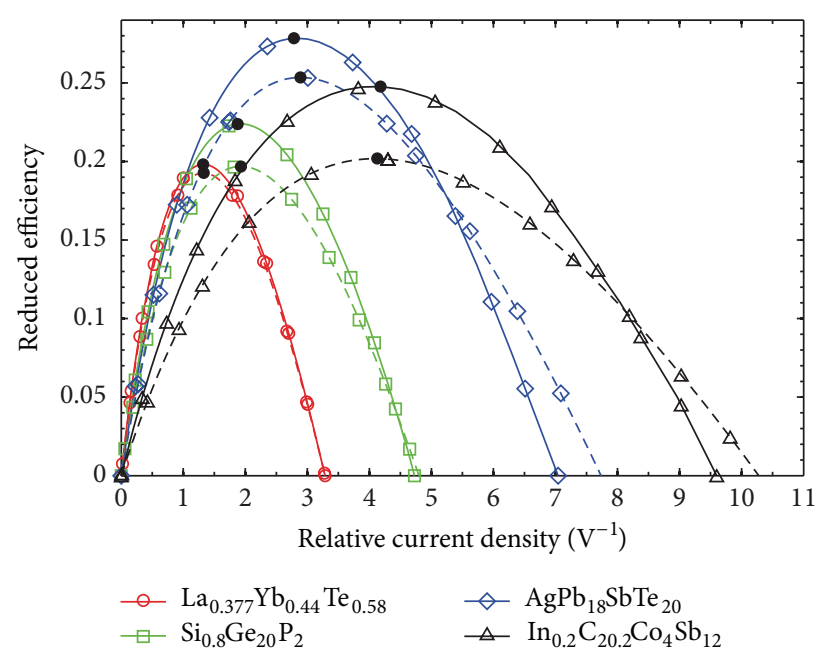

(b)

Figure 5: Variation of reduced efficiency versus $u\left(T_{\mathrm{av}}\right)$ (relative current density at $T_{\mathrm{av}}$ ) for the materials used in (a) $n 1-\mathrm{leg}$ and (b) $n 2$-leg. The solid and dashed lines indicate results of exact and approximate method, respectively.

TABLE 4: Design and performance characteristics of $p 1-n 2$ generator at maximum output power, calculated through exact method.

\begin{tabular}{lc}
\hline Parameters & Exact $(p 1-n 2)$ \\
\hline$L(\mathrm{~mm})($ input $)$ & 10 \\
\hline$A_{p}\left(\mathrm{~mm}^{2}\right)$ (input) & 100 \\
\hline Calculated $Q_{\mathrm{in}}(\mathrm{W})$ & 41.07 \\
\hline Calculated $Q_{\mathrm{rej}}(\mathrm{W})$ & 31.73 \\
\hline Calculated $P_{e}(\mathrm{~W})$ & 9.33 \\
\hline Calculated peak efficiency, $\eta(\%)$ & 22.72 \\
\hline$A_{n, \mathrm{opt}}\left(\mathrm{mm}^{2}\right)$ & 84.03 \\
\hline$L_{p, 1}, L_{p, 2}, L_{p, 3}, L_{p, 4}, L_{p, 5}(\mathrm{~mm})$ & $2.762,3.274,1.574,0.841,1.831$ \\
\hline$L_{n, 1}, L_{n, 2}, L_{n, 3}, L_{n, 4}(\mathrm{~mm})$ & $0.540,6.521,1.784,1.589$ \\
\hline$I(\mathrm{~A})$ & 35.52 \\
\hline$R_{L, \mathrm{opt}}(\mathrm{m} \Omega)$ & 7.4 \\
\hline
\end{tabular}

TABLE 5: Reduced efficiency of arrangements with increasing number of elements.

\begin{tabular}{lcccc}
\hline \multirow{2}{*}{ Number of elements } & \multicolumn{4}{c}{ Leg } \\
& $p 1$ & $p 2$ & $n 1$ & $n 2$ \\
\hline 1 & 20.61 & 24.66 & 20.32 & 24.76 \\
2 & 25.87 & 24.66 & 25.35 & 28.68 \\
3 & 27.41 & 26.15 & 28.42 & 30.91 \\
4 & 28.46 & 27.54 & 28.19 & 30.53 \\
5 & 29.32 & 29.02 & - & - \\
\hline
\end{tabular}

compared with those of exact method. These tables show that, in Swanson et al.s method, design and characteristic properties of $p$-type and $n$-type legs depend on each other, while in the exact method $p$-type legs are designed separately and independently of $n$-type legs. The differences of Swanson et al's results compared to exact ones are presented in parenthesis in these tables. The tables indicate that Swanson et al's method could cause a difference of up to $4.1 \%$ in inlet heat, $7.8 \%$ in outlet heat, $5.8 \%$ in generated power, $3.3 \%$ in efficiency, $20.3 \%$ in $n$-type leg cross section area, $9.1 \%$ in element lengths, $7.1 \%$ in current, and $14.0 \%$ in external resistance. In these tables, the two highest differences belong to the external resistance and $n$-type leg cross sections area (i.e., $14 \%$ and $20.3 \%$, resp.). Swanson et al. [13] has referred to such differences by optimizing the efficiency for the two following cases: constant $R_{L} / R=$ optimum value, variable $A_{n} / A_{p}$, and variable $R_{L} / R$, constant $A_{n} / A_{p}=$ optimum value. In this paper, the two preceding cases have been investigated, in four generators, and the results are shown in Figures 7(a)-7(d), through the curves of efficiency with respect to electrical current. In Swanson et al.s method, the amount of calculated electrical power is not equal to that of thermal power obtained through satisfaction of the energybalance equation. This is because of the approximations and use of temperature average properties of materials. Therefore, there exists residual power shown in Tables 2 and 3. The exact method satisfies the overall energy-balance equation completely and thus there is no residual power.

The compatibility factor of the materials used in $n$ type and $p$-type legs has also been calculated using the approximate relation (10) and indicated with dashed lines in Figures 5 and 6, respectively. A comparison of results with the ones of exact method reveals that relation (10) yields somewhat exact results and there is not a considerable difference in compatibility factor whereas there is a noticeable difference in reduced efficiency.

\section{Conclusion}

Four STEGs with the best known thermoelectric materials have been optimized for operating between 300 and $1300 \mathrm{~K}$. The maximum theoretically achievable efficiency has been calculated assuming insulated outside surface area and 


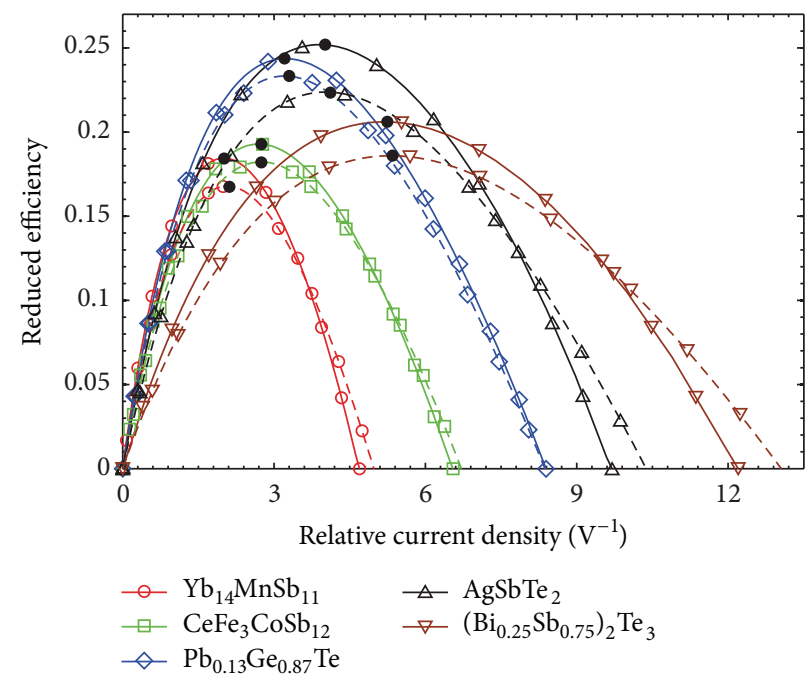

(a)

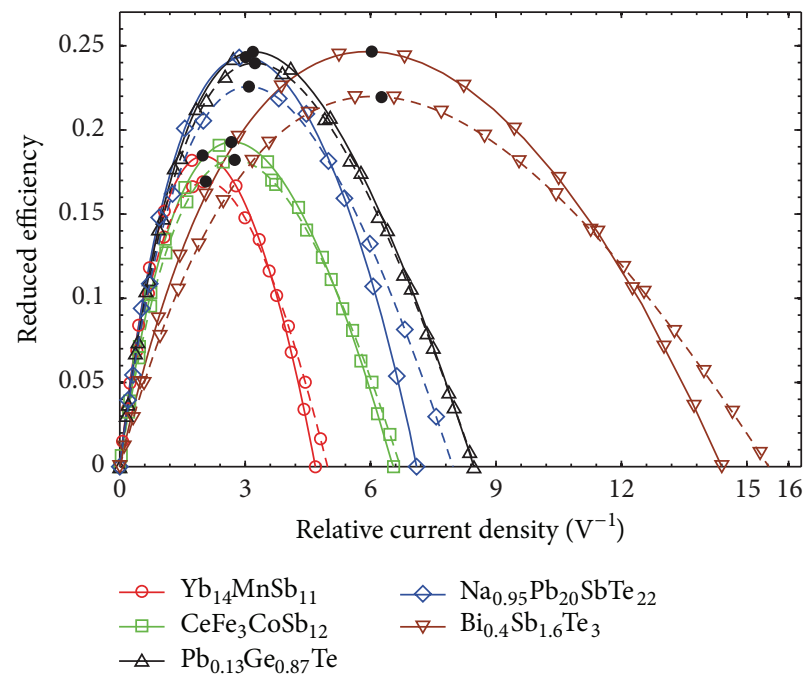

(b)

Figure 6: Variation of reduced efficiency versus $u\left(T_{\mathrm{av}}\right)$ (relative current density at $T_{\mathrm{av}}$ ) for the materials used in (a) $p 1-\mathrm{leg}$ and (b) $p 2$-leg. The solid and dashed lines indicate results of exact and approximate method, respectively.

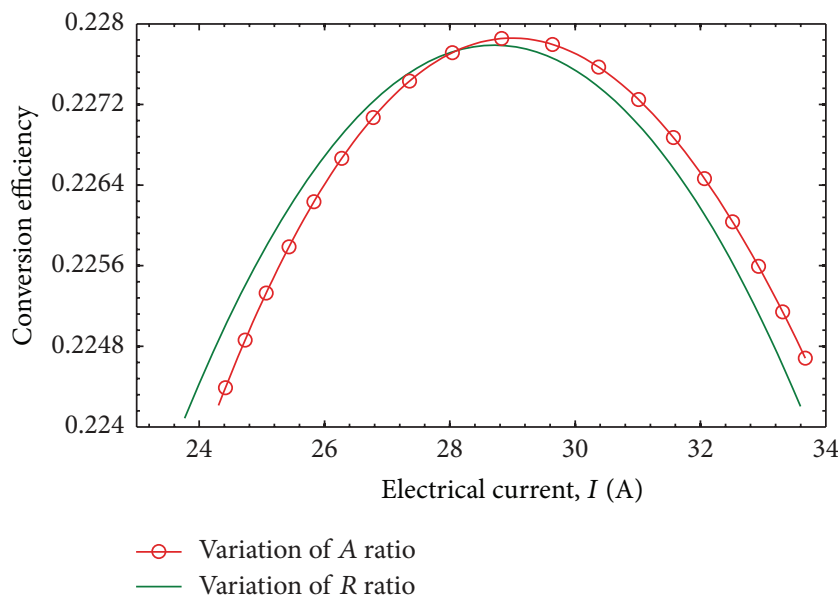

(a)

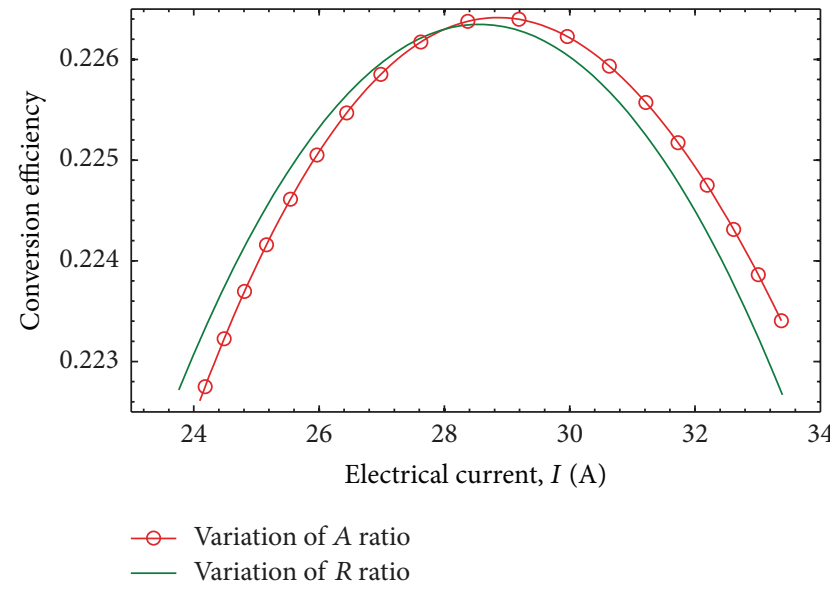

(c)

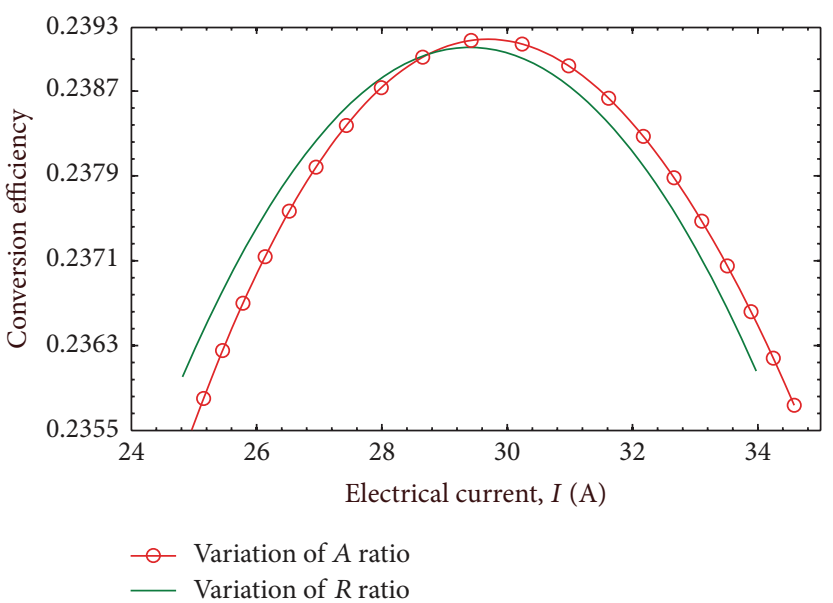

(b)

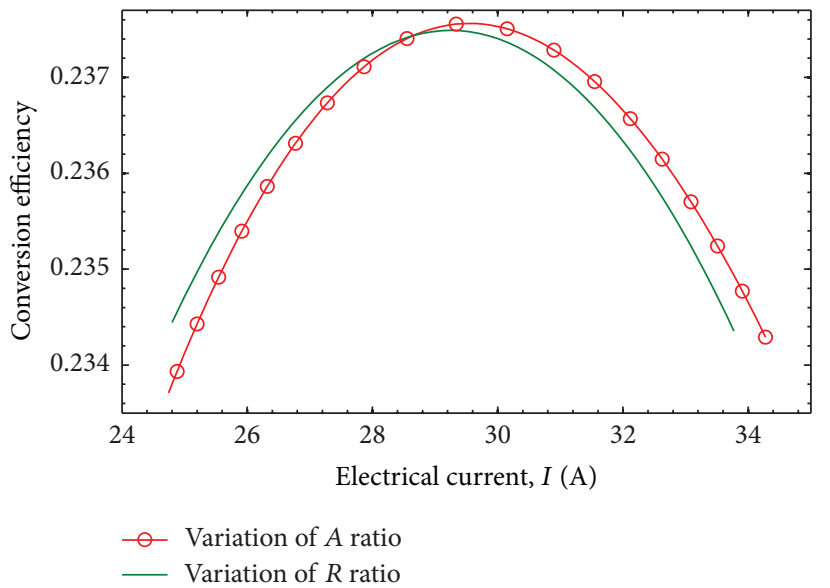

(d)

FIGURE 7: Variation of efficiency with respect to electrical current for the two following cases: constant $R_{L} / R=$ optimum value, variable $A_{n} / A_{p}$, and variable $R_{L} / R$, constant $A_{n} / A_{p}=$ optimum value. (a)-(d) represent $p 1-n 1, p 1-n 2$, $p 2-n 1$, and $p 2-n 2$ generators, respectively. 
negligible contact resistance. Design and performance characteristics of the generators have been calculated at maximum efficiency using exact and Swanson et al.s method. Maximum efficiency of $23.08 \%$ has been obtained for the best arrangement, which shows $4.98 \%$ increase in comparison with the best of the previous published results in a similar temperature range ( 298 and $1273 \mathrm{~K}$ ). Compatibility factor of the arrangements has been calculated through both exact and Swanson et al's method. Satisfactory compatibility has been observed for the materials in each arrangement. All the results of exact and Swanson et al.'s method have been compared. It has been observed that Swanson et al's method could cause a difference of up to $20 \%$ in some characteristics despite its sufficiently good results in calculation efficiency. Enhancing thermoelectric efficiency opens the way to generate electrical power especially by using waste heat as source. Owing to the great deal of attempt and investigation to improve thermoelectric properties, especially based on nanotechnology, this direct energy conversion method and consequently the exergy optimization are awaiting a bright future.

\section{Nomenclature}

\section{Variables}

$\begin{array}{ll}A: & \text { Cross section area }\left(\mathrm{m}^{2}\right) \\ I: & \text { Electrical current }(\mathrm{A}) \\ J: & \text { Electrical current density }\left(\mathrm{Am}^{-2}\right) \\ k: & \text { Thermal conductivity }\left(\mathrm{Wm}^{-1} \mathrm{~K}^{-1}\right) \\ L: & \text { Length of legs }(\mathrm{m}) \\ L_{p, 1}, \ldots, L_{n, 1}, \ldots: & \text { Length of segments }(\mathrm{m}) \\ P_{e}: & \text { Output electrical power }(\mathrm{W}) \\ \mathrm{Q}: & \text { Heat power }(\mathrm{W}) \\ R: & \text { Electrical resistance }(\Omega) \\ T: & \text { Temperature }(\mathrm{K}) \\ u: & \text { Relative electrical current density }\left(\mathrm{V}^{-1}\right) \\ W: & \text { Work output (W) } \\ x: & \text { Coordinate originated from hot source } \\ Z: & \text { (m) } \\ Z T: & \text { Figure of merit (FOM) }\left(\mathrm{K}^{-1}\right) \\ & \text { Dimensionless figure of merit. }\end{array}$

\section{Greek Symbols}

$\alpha$ : Seebeck coefficient $\left(\mathrm{VK}^{-1}\right)$

$\eta$ : Efficiency

$\eta_{c}:$ Carnot efficiency

$\eta_{r}$ : Reduced efficiency

$\gamma$ : Thomson coefficient $\left(\mathrm{VK}^{-1}\right)$

$\pi$ : Peltier coefficient $(\mathrm{V})$

$\rho$ : Electrical resistivity $(\Omega \cdot \mathrm{m})$.

\section{Scripts}

': Derivative with respect to $x$

av: Average

$c$ : Cold source

$h$ : Hot source in: Input

int: Internal

$j$ : Index for segment number

L: $\quad$ Electrical load

n: $n$-leg

opt: Optimum

p: p-leg

rej: Reject or output.

\section{Competing Interests}

The authors declare that they have no competing interests.

\section{References}

[1] S. B. Riffat and X. Ma, "Thermoelectrics: a review of present and potential applications," Applied Thermal Engineering, vol. 23, no. 8, pp. 913-935, 2003.

[2] K. Yazawa and A. Shakouri, "Thermoelectric topping cycles with scalable design and temperature dependent material properties," Scripta Materialia, vol. 111, pp. 58-63, 2016.

[3] H. Tian, X. Sun, Q. Jia, X. Liang, G. Shu, and X. Wang, "Comparison and parameter optimization of a segmented thermoelectric generator by using the high temperature exhaust of a diesel engine," Energy, vol. 84, pp. 121-130, 2015.

[4] J. P. Heremans, V. Jovovic, E. S. Toberer et al., "Enhancement of thermoelectric efficiency in $\mathrm{PbTe}$ by distortion of the electronic density of states," Science, vol. 321, no. 5888, pp. 554-557, 2008.

[5] G. J. Snyder and E. S. Toberer, "Complex thermoelectric materials," Nature Materials, vol. 7, no. 2, pp. 105-114, 2008.

[6] L. I. Soliman, M. M. Nassary, H. T. Shaban, and A. S. Salwa, "Influence of Se on the electron mobility in thermal evaporated $\mathrm{Bi}_{2}\left(\mathrm{Te}_{1-x} \mathrm{Se}_{x}\right)_{3}$ thin films," Vacuum, vol. 85, no. 3, pp. 358-364, 2010.

[7] L. T. Hung, N. Van Nong, G. J. Snyder et al., "High performance p-type segmented leg of misfit-layered cobaltite and halfHeusler alloy," Energy Conversion and Management, vol. 99, pp. 20-27, 2015.

[8] G. Chen, M. Dresselhaus, and Z. Ren, "Nanocomposites with high thermoelectric figures of merit," US Patent App 20, 090/068, 465, 2008.

[9] Z. Ren, B. Poudel, G. Chen, Y. Lan, D. Wang, and Q. E. A. Hao, "Methods for high figure-of-merit in nanostructured thermoelectric materials," US Patent App. 11/949, 353, 2007.

[10] Y. S. Kang, M. Niino, I. A. Nishida, and J. Yoshino, "Development and evaluation of 3-stage segmented thermoelectric elements," in Proceedings of the 17th International Conference on Thermoelectrics (ICT'98), pp. 429-432, May 1998.

[11] G. J. Snyder and T. Caillat, "Using the compatibility factor to design high efficiency segmented thermoelectric generators," Materials Research Society Symposium Proceedings, vol. 793, pp. 37-42, 2003.

[12] B. Sherman, R. R. Heikes, and R. W. Ure Jr., "Calculation of efficiency of thermoelectric devices," Journal of Applied Physics, vol. 31, no. 1, pp. 1-16, 1960.

[13] B. W. Swanson, E. V. Somers, and R. R. Heikes, "Optimization of a sandwiched thermoelectric device," Journal of Heat Transfer, vol. 83, no. 1, pp. 77-82, 1961.

[14] R. G. Moore, "Exact computer solution of segmented thermoelectric devices," Advanced Energy Conversion, vol. 2, pp. 183195, 1962. 
[15] M. S. El-Genk and H. H. Saber, "High efficiency segmented thermoelectric unicouple for operation between 973 and $300 \mathrm{~K}$," Energy Conversion and Management, vol. 44, no. 7, pp. 10691088, 2003.

[16] C. Hadjistassou, E. Kyriakides, and J. Georgiou, "Designing high efficiency segmented thermoelectric generators," Energy Conversion and Management, vol. 66, pp. 165-172, 2013.

[17] T. Ming, Y. Wu, C. Peng, and Y. Tao, "Thermal analysis on a segmented thermoelectric generator," Energy, vol. 80, pp. 388399, 2015

[18] T. Ursell and G. Snyder, "Compatibility of segmented thermoelectric generators," in Proceedings of the 21st International Conference on Thermoelectrics (ICT '02), pp. 412-417, Long Beach, Calif, USA, 2002.

[19] O. Yamashita, S. Tomiyoshi, and K. Makita, "Bismuth telluride compounds with high thermoelectric figures of merit," Journal of Applied Physics, vol. 93, no. 1, pp. 368-374, 2003.

[20] S. Fan, J. Zhao, J. Guo, Q. Yan, J. Ma, and H. H. Hng, "P-type Bi0.4 Sb1.6 Te3 nanocomposites with enhanced figure of merit," Applied Physics Letters, vol. 96, no. 18, Article ID 182104, 2010.

[21] O. Yamashita and S. Tomiyoshi, "High performance n-type bismuth telluride with highly stable thermoelectric figure of merit," Journal of Applied Physics, vol. 95, no. 11, pp. 6277-6283, 2004.

[22] M. Subramanian, T. He, and J. Krajewski, "High performance thermoelectric materials and their method of preparation," US Patent Application 12/785,605, 2010.

[23] H. Wang, J.-F. Li, M. Zou, and T. Sui, "Synthesis and transport property of $\mathrm{AgSbTe}_{2}$ as a promising thermoelectric compound," Applied Physics Letters, vol. 93, no. 20, Article ID 202106, 2008.

[24] P. F. P. Poudeu, J. D’Angelo, A. D. Downey, J. L. Short, T. P. Hogan, and M. G. Kanatzidis, "High thermoelectric figure of merit and nanostructuring in bulk p-type Na1$\mathrm{xPbmSbyTem+2,"} \mathrm{Angewandte} \mathrm{Chemie-International} \mathrm{Edition,}$ vol. 45 , no. 23, pp. 3835-3839, 2006.

[25] K. F. Hsu, S. Loo, F. Guo et al., "Cubic AgPbmSbTe2+m: bulk thermoelectric materials with high figure of merit," Science, vol. 303, no. 5659, pp. 818-821, 2004.

[26] Y. Gelbstein, B. Dado, O. Ben-Yehuda, Y. Sadia, Z. Dashevsky, and M. P. Dariel, "Highly efficient Ge-rich $\mathrm{Ge}_{x} \mathrm{~Pb}_{1-x} \mathrm{Te}$ thermoelectric alloys," Journal of Electronic Materials, vol. 39, no. 9, pp. 2049-2052, 2010.

[27] X. W. Wang, H. Lee, Y. C. Lan et al., "Enhanced thermoelectric figure of merit in nanostructured n-type silicon germanium bulk alloy," Applied Physics Letters, vol. 93, no. 19, Article ID 193121, 2008.

[28] J.-P. Fleurial, A. Borshchevsky, T. Caillat, D. T. Morelli, and G. P. Meisner, "High figure of merit in Ce-filled skutterudites," in Proceedings of the 15th International Conference on Thermoelectrics (ICT '96), pp. 91-95, March 1996.

[29] A. F. May, J.-P. Fleurial, and G. J. Snyder, "Optimizing thermoelectric efficiency in $\mathrm{La}_{3-x} \mathrm{Te}_{4}$ via $\mathrm{Yb}$ substitution," Chemistry of Materials, vol. 22, no. 9, pp. 2995-2999, 2010.

[30] S. R. Brown, S. M. Kauzlarich, F. Gascoin, and G. Jeffrey Snyder, " $\mathrm{Yb}_{14} \mathrm{MnSb}_{11}$ : new high efficiency thermoelectric material for power generation," Chemistry of Materials, vol. 18, no. 7, pp. 1873-1877, 2006.

[31] C. A. Domenicali, "Stationary temperature distribution in an electrically heated conductor," Journal of Applied Physics, vol. 25, no. 10, pp. 1310-1311, 1954.
[32] G. J. Snyder and T. S. Ursell, "Thermoelectric efficiency and compatibility," Physical Review Letters, vol. 91, no. 14, 2003.

[33] J.-P. Fleurial, A. Borshchevsky, T. Caillat, and R. Ewell, "New materials and devices for thermoelectric applications," in Proceedings of the 32nd Intersociety Energy Conversion Engineering Conference (IECEC '97), vol. 2, pp. 1080-1085, Honolulu, Hawaii, USA, August 1997. 


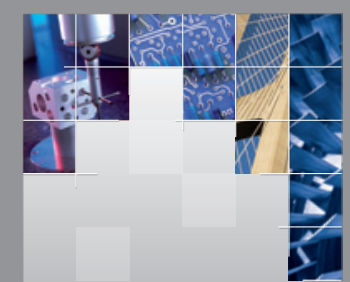

\section{Enfincering}
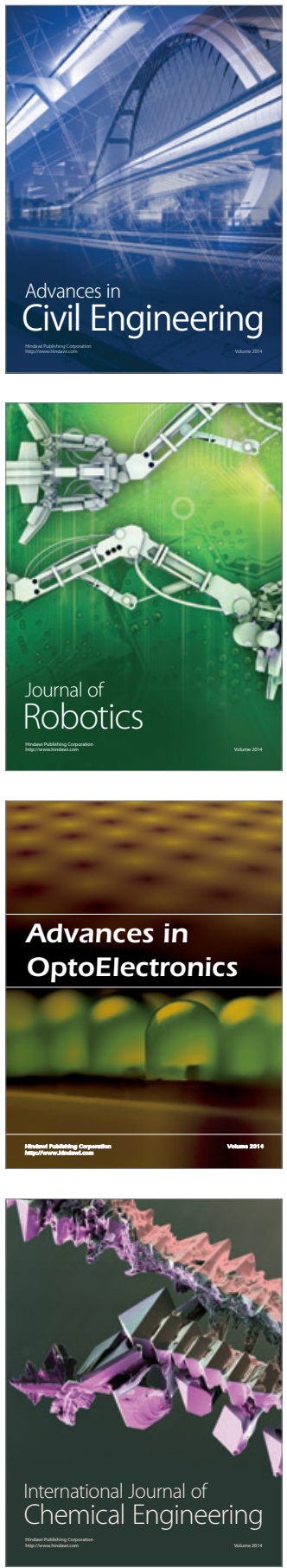

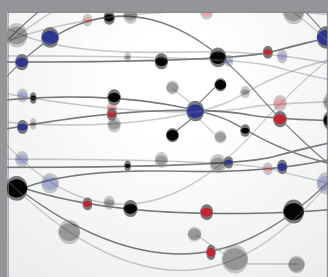

The Scientific World Journal

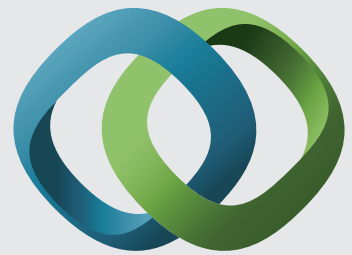

\section{Hindawi}

Submit your manuscripts at

http://www.hindawi.com
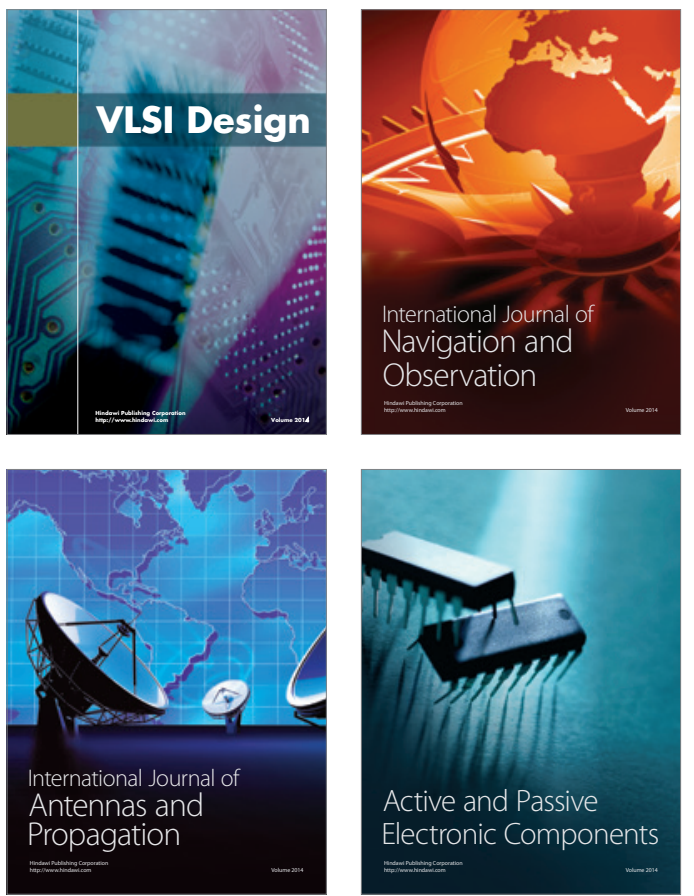
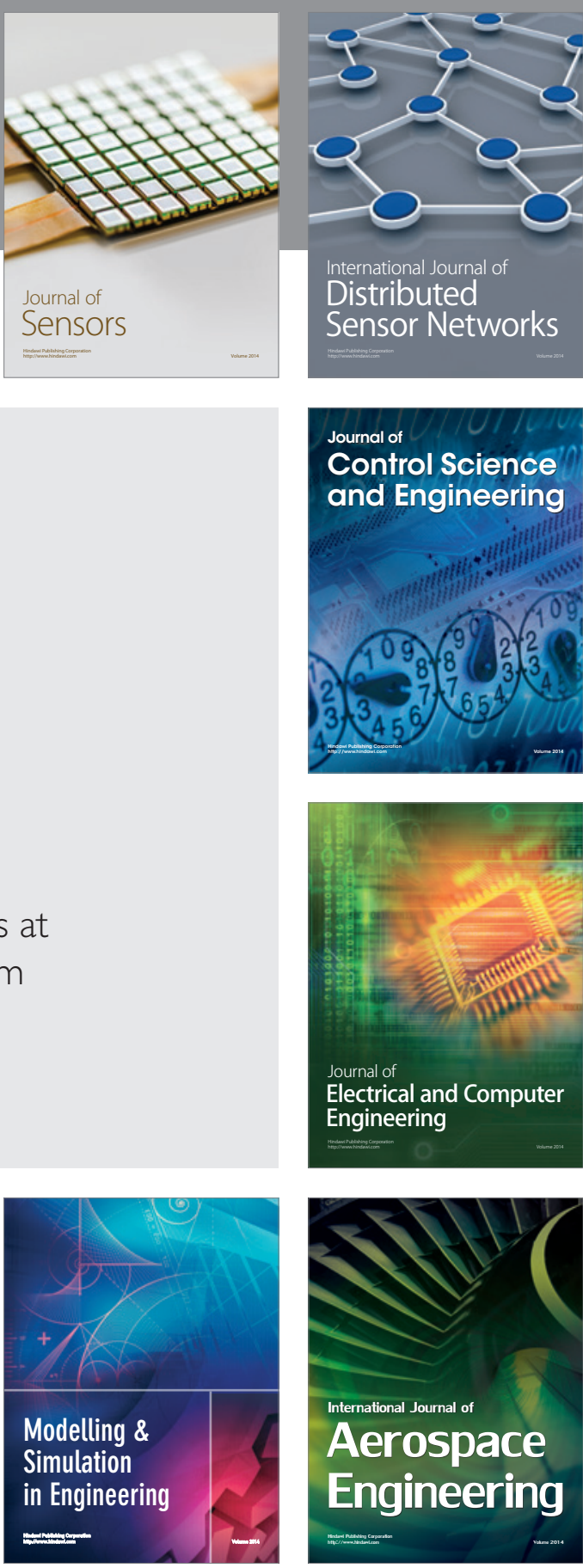

International Journal of

Distributed

Sensor Networks

Journal of

Control Science

and Engineering
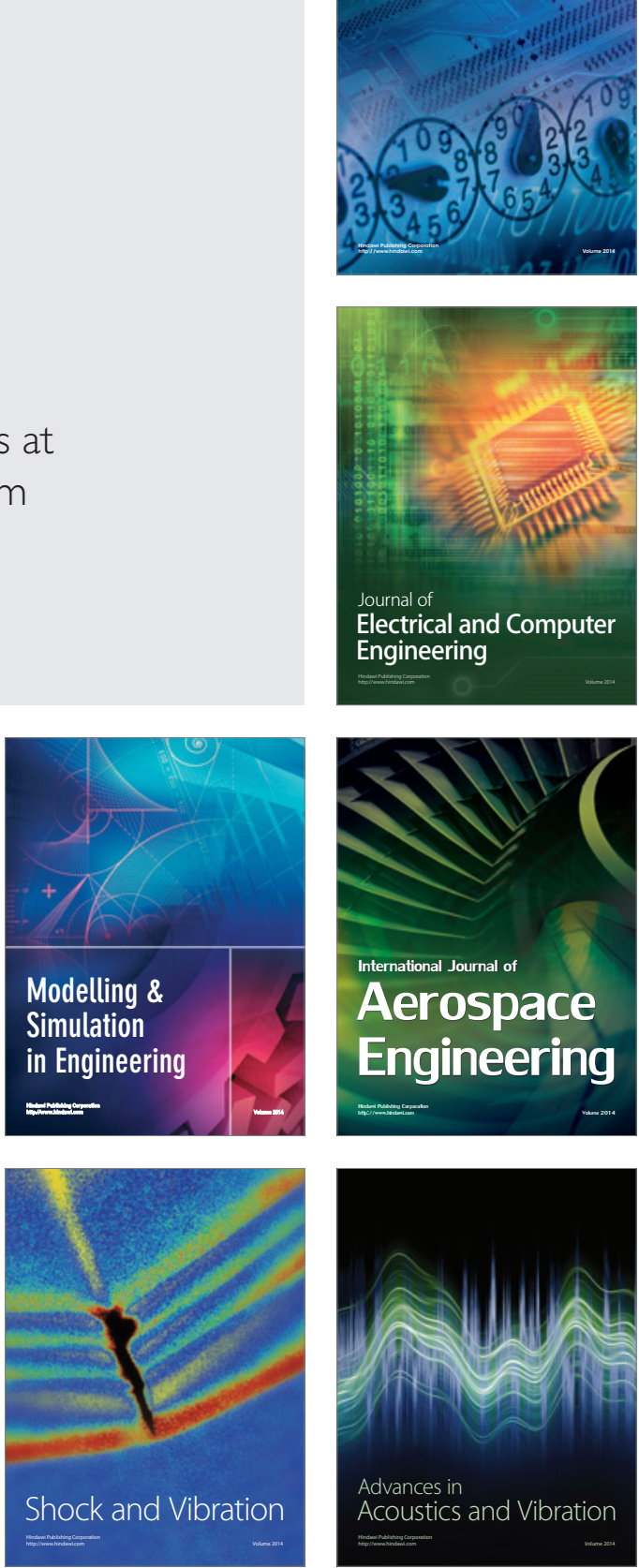